ITC 3/48

Journal of Information Technology and Control

Vol. 48 / No. 3 / 2019

pp. $464-486$

DOI 10.5755/j01.itc.48.3.22189
Computer Methods for Non-invasive Measurement and Control of Two-phase Flows: A Review Study

Crossef http://dx.doi.org/10.5755/j01.itc.48.3.22189

\title{
Computer Methods for
}

Non-invasive Measurement

and Control of Two-phase

Flows: A Review Study

\author{
Radoslaw Wajman \\ Institute of Applied Computer Science at Lodz University of Technology, \\ Stefanowskiego 18/22, 90-924 Lodz, Poland; e-mail: radoslaw.wajman@p.lodz.pl
}

Corresponding author: radoslaw.wajman@p.lodz.pl

Nowadays, the application of advanced technologies in modern production systems is the main trend of development and technological progress in many industrial sectors. It is due to the still growing trends of energy-saving and production quality enhancement. Wherever in the production process, the phase mixture is transported and it is not optimal or not economical, there is a need to develop a system which would be able to prevent any construction disaster, unexpected production line stopping or situation where for reasons of bad flow parameters, the final product is defective. This paper studies various sensors, measurement techniques and computer methods for signal processing and analysis to diagnose and control two-phase flows. Due to the possibility that the invasive measurement disturbs the process and changes it parameters and behaviour especially in the location just after the measurement point and simultaneously does not provide any information about these changes it is unreliable for the diagnosis or control. Therefore, the non-invasive techniques commonly used for measurement of flows parameters are described. Depending on the industrial demands, many applications examples for non-invasive two-phase flows measurement and monitoring are given. This description for identifying the flow parameters is divided into features categories of this phenomenon as void fraction distribution, velocity profile and flow regime. However, from these methods the high accuracy and short processing time are expected. The continued observation and monitoring of the process deliver knowledge about the dynamic states of the flow to control it more efficiently. Therefore, the development of advanced process control is one of the most important challenges to keep the flow regime on the given level and for instant and long-term energy saving, quality improvement.

KEYWORDS: identification, control, non-invasive measurement, process tomography, 3D electrical tomography, two-phase flow. 


\section{Introduction}

The two-phase flow (TPF) process is a part of many technological lines in the industry and still, it is one of the most studied phenomena in fluid and particles mechanics [38]. Numerous research works have been done in order to learn and describe this phenomenon what may be testified not only by the sophisticated simulation models e.g. Computational Fluid Dynamics (CFD) [9] but also by new concepts of diagnostics systems. Furthermore, new optimisation methods and computer algorithms for control are also being designed.

The still growing interest strongly depends on their great practical significance in many industrial branches like food, biotechnology, bioprocess, environmental, chemistry and petrol engineering. That is because the TPFs are an important and ubiquitous component of numerous industrial processes like the aeration processes [144, 68], chemical reactors [72], processes of flotation [147]. Some examples of TFP applications are summarized in Table 1.

From the hydrodynamic point of view, the TPF mixtures identification is focused on evaluations of flow patterns, flow resistance and void fraction of the mix- ture $[34,125,26]$. Additionally, to describe the mass transfer it is required to determine other flow parameters like mass transfer coefficient, gas bubbles coalescence and finally the interfacial surface area. So far, many of research works presented in the literature have been done to solve these issues. On the other hand, due to the complicated mechanism of flow dynamics, often connected with difficulties in its description from the mathematical point of view and due to the complicated measurement methods the further and new studies are highly expected.

The correct and optimal functioning of the industrial processes involving the TPFs depends on various, sophisticated tasks of measurement, diagnosis and control as it is depicted on the flow diagram in Figure 1.

The growing needs of industry for a simple, versatile, relatively inexpensive, non-invasive and rapid method of process monitoring and control for TPFs remain apparent. The knowledge of the characteristics and types of flow is required while designing production lines or numerical modelling algorithms [106,69] to predict or/and to prevent the malfunctioning of the process.

Table 1

Examples of TFP applications in the industry

\begin{tabular}{|c|c|c|}
\hline $\begin{array}{l}\text { industry / } \\
\text { phenomena }\end{array}$ & application & description \\
\hline \multirow{2}{*}{$\begin{array}{l}\text { aeration } \\
\text { systems }\end{array}$} & sewage aeration & biological sewage treatment plants $[16,46]$ \\
\hline & aerobic bacteria & injection of free oxygen to ensure the bacteria growth [112] \\
\hline \multirow{5}{*}{$\begin{array}{l}\text { bio- and } \\
\text { petrochemical } \\
\text { processes }\end{array}$} & $\begin{array}{l}\text { bubbles columns in physical } \\
\text { and chemical processes }\end{array}$ & $\begin{array}{l}\text { identification of bubbles to study mass transfer in chemical reactions } \\
\text { [30,101], evaluation of air-bubbles plumes existence [2] }\end{array}$ \\
\hline & \multirow{2}{*}{ air-lift columns } & intensity of the process depends on the bubbles size $[5,71,19]$ \\
\hline & & control of the gas stream to force the liquid movement $[12,20]$ \\
\hline & \multirow{2}{*}{ ejectors } & flotation processes in the extractive industry [166] \\
\hline & & sedimentation processes to precipitate some fractions of the liquid [93], \\
\hline $\begin{array}{l}\text { chemical } \\
\text { reactors }\end{array}$ & electrolysis & $\begin{array}{l}\text { the intensity of the process identified from the gas phase }[109,81] \text {, } \\
\text { evaluated size of the gas bubbles indicates the process quality }\end{array}$ \\
\hline heating devices & heat exchange & gas existence is undesirable and denotes the boiling liquid [139] \\
\hline cavitation & rotational pump & $\begin{array}{l}\text { detection of this phenomena warns of pump's blades erosion or leakage } \\
{[85,169]}\end{array}$ \\
\hline
\end{tabular}


Figure 1

The flow diagram with measurement, diagnosis and control tasks processed in the cloud for TPFs handling in the innovative industry of $4^{\text {th }}$ generation

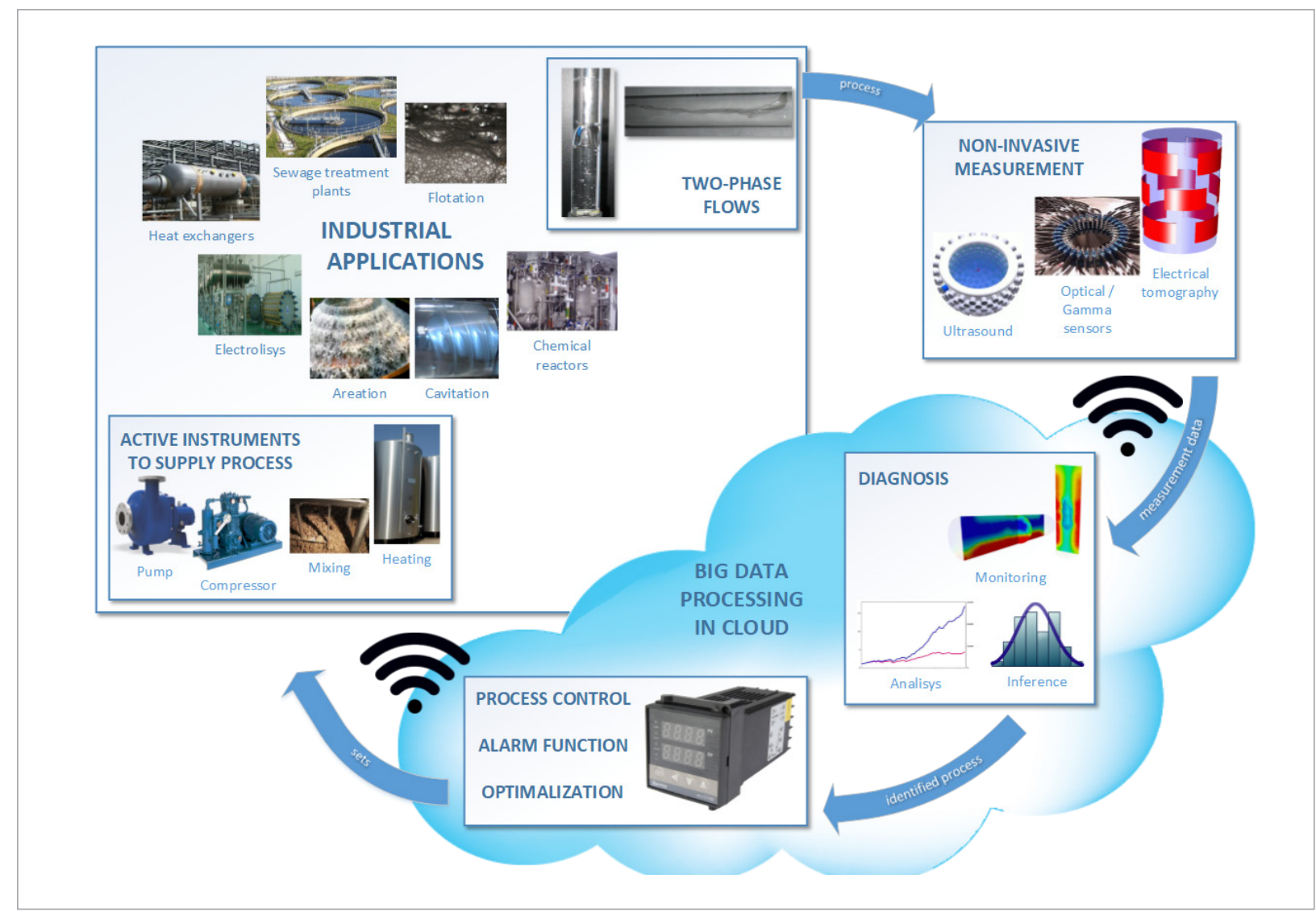

Nowadays, the application of advanced technologies in modern production systems is the main trend of development and technological progress in many industrial sectors. It is due to the growing trends of energy-saving and production quality enhancement. Wherever in the production process, the phase mixture is transported and it is not optimal or not economic, there is a need to develop a system which would be able to prevent any construction disaster, unexpected production line stopping or situation where for reasons of bad flow parameters, the final product is defective. Such a solution could also be irreplaceable when a flow process requires constant supervision, or when the work environment would be a danger to the safety or employees' health and simultaneously it is required a continued, automated, non-invasive and efficient monitoring of inaccessible parts of pipelines.

\section{Lessons Learned from the Review}

This review provides the reader with the fundamentals and new applications of diagnosis and control of TPF processes as well as points out the future development directions in the context of advance and innovative information technologies. The summarised state-of-the-art given in this review for numerous engineers and young researches starting their adventure with the TPF s would deliver valuable lessons about:

_ the non-invasive measurement techniques commonly applied for TPF scanning categorised regarding their physics phenomena,

_ the TPF parameters categorisation,

_ the computer methods of measurement data processing and analysis involved for TPF identification, 
- the artificial intelligence techniques applied for inferencing about TPF parameters and process control strategy,

- the directions of IT innovations developments for TPF handling in a frame of industry 4.0 revolution.

\section{Two-phase Flows Non-invasive Measurements Techniques}

The main aspect of many identification and control systems is a measurement of industrial flows' features. Since many years the research conducted on the two-phase gas-liquid flows still does not deliver consistent answers to many questions according to this phenomenon [38]. It is because of its stochastic nature as well as its dynamics but also it is related to the research capabilities. In the case of these flow processes, the diagnostic methods developed so far are based on usage of most sophisticated measurement techniques [22]. Just as a technical advancement grows many flow measurement techniques were developed starting from mechanical through the electrical unto radiation. The measurement precision has continuously raised and its variety differed concerning the liquid or gas. In the beginning, most of them interfered with changing of the process features $[160,148]$ e.g. mechanical, manometric, impulse flow- meters or rotameters. Though, the development in this field has been focused on non-invasive methods using electric, ultrasound (Doppler Effect) or hard radiation sensors. Since the invasive measurement disturbs the process and changes it parameters and behaviour in the location just after the measurement point and simultaneously does not provide any information about these changes it is unreliable for the diagnosis or control. However, there are some kinds of methods which involve a special tracer system to expand the flow features by the assumption that it is less intrusive.

Below, the state of the art in a field of flow measuring is provided. This description, however, focusing only on non-invasive groups of methods, is divided considering the sensors' physical matter and starts from single-measurement based method (1D) through the tomographic based methods (2D and 3D). Figure 2 shows the diagram of possible non-invasive sensing techniques grouped by their physical matter and dimension abilities.

\section{Electrical methods}

The flow can be characterized by electrical properties. The flowing phases can be conductive, dielectric or magnetic. The usage of a conductance sensor for phases identification between gas and liquid is not an innovative solution. In the past, it was commonly applied in multiphase flows to evaluate the local velo-

\section{Figure 2}

Non-invasive sensors for flows diagnosis with dimension measurement strategies

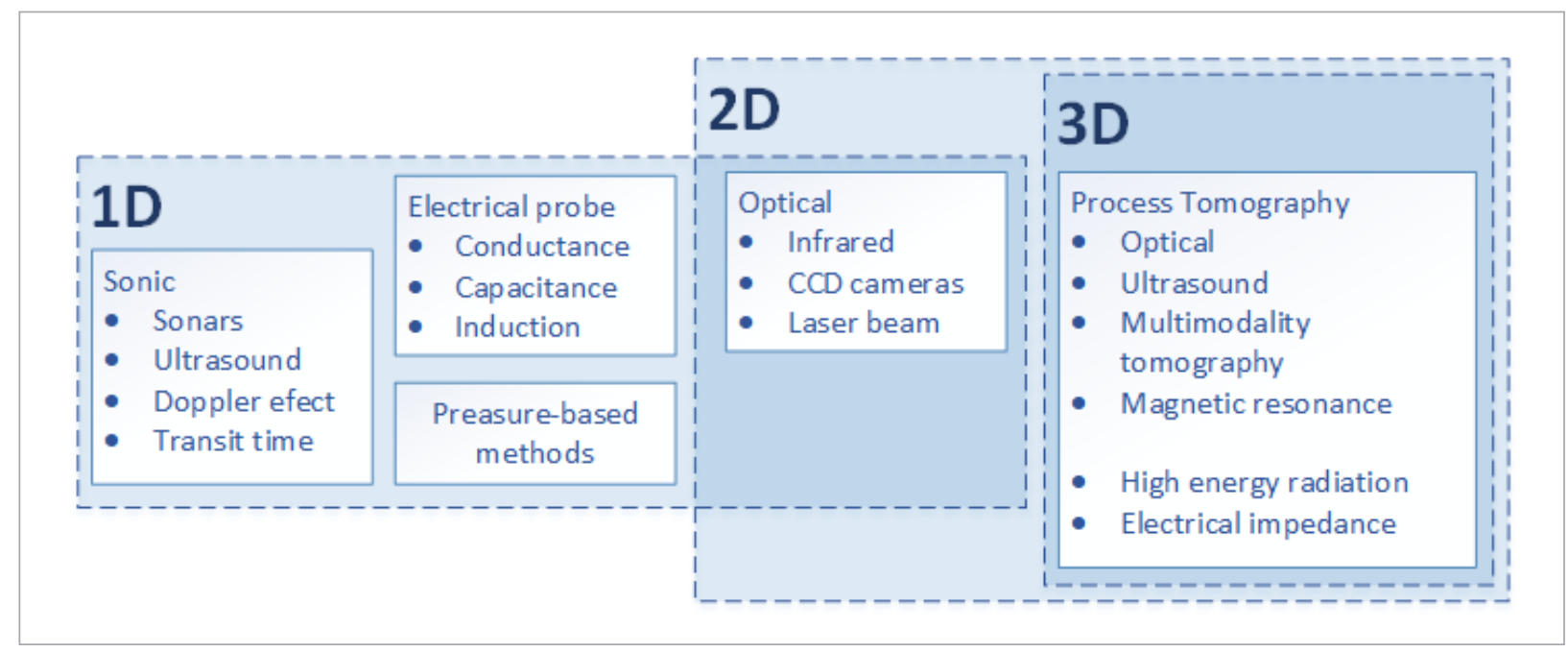


city distribution or volume of gas fraction. Still, there are lots of limitations or required assumptions using conductance-based measurements as it has actually been reported in [88]. The authors of this work examined the oil-in-water bubbly vertical flow to evaluate the oil velocity distribution and distribution of oil fraction in the basis of conductance probe composed of two sensors. This type of radial sensors was successfully used also by [49]

for the flow pattern and holdup phenomena investigation of low-velocity oil-water flows in a vertical upward small diameter pipe.

If the conductive phase is the solid phase and non-conducting phase isolates electrodes from the conductive phase, inductive sensors are more suitable. This technique based on an induced voltage across a liquid moving through a magnetic field has been successfully used to measure the mean velocity of the conductive fluid in the single-phase flows [133].

Similar, the proven solution in case of non-conductive phase is the measurement of electrical capacitance. Such a method was successfully applied in [57] to measure the water holdup based on water layer thickness in horizontal pipes. In [167], in turn, the authors designed the capacitance sensor in the form of double helix and similarly were able to evaluate the holdup in the oil-water horizontal flow. The liquid holdup of cryogenic TPF measurement system with a capacitance ( 2 electrodes) sensor was designed [25]. The same shape of electrodes can be seen in the system in [8].

\section{Optical, vision}

Another group of methods that are definitely non-invasive but require transparent part of the pipeline are methods based on photography. There are numerous solutions where this approach only supports the measurements performed using other techniques [61] or may play the main role in monitoring. In [155], the authors used the high-speed camera and the images of flow structure of different flow regimes were caught to visual analysis or visual assessment. Some examples of image analysis for identification of flow patterns in oil-water upward flow may be found in [48]. Moreover, in the literature, some examples that apply complex algorithms of image processing to investigate the flow specificity may be found. do Amaral et al. [7] captured the series of flow images using a high-speed camera and designed a computer method to extract quantitative parameters of turbulent flows in horizontal pipes. The different steps of the segmentation phase for captured images were implemented. It was shown there that this method provided the results of bubble dimensions, velocity and frequency.

The visual observation of the flow patterns becomes difficult when the mixture velocity increases or the pipe-wall is no longer clear. Under these conditions, there is a need to search other techniques to clarify the flow regime identification.

\section{Tomographic techniques for non-invasive flows measurement}

One of the methods for the dynamic processes monitoring is the Process Tomography (PT). This technique of process (object) imaging provides the possibility of an investigation of structural complexity of physical and chemical phenomena without the need for interference in it. It is widely applied for visualisation and monitoring of various processes due to its variety of physical quantities. It collects measurements from sensors located around the process volume and reconstructs 2D (two Dimensional, cross-sectional) or 3D image of character, density or components distribution inside the measurement volume. PT significantly differs from other classical methods based on e.g. photo or thermo vision cameras. The most demanded feature of PT is its non-invasive (sensors should not be mounted inside the process) and non-intrusive (should not interference the process and change it) measurement.

Previously described measurement techniques have not engaged any sophisticated computer methods and algorithms. Computers have been used mostly for collecting and organising measurement data for purposes of future analysis determining required flow parameters.

The process tomography applies computer techniques just on measurement stage. First, the raw acquired measurement data need to be reorganised removing duplicated and negligible values. Then, to reconstruct the image of the examined space, the complex computer methods are applied which involve advanced computational challenging algorithms for computer modelling, statistical calculations and artificial intelligence $[14,149,152]$. 
According to the applied energy source PT can be categorised into two main groups [138]: hard-field (optical, ultrasound, magnetic resonance imaging, high-energy $\mathrm{X}$ and gamma rays) and soft-field tomography (electric and magnetic phenomena). PT techniques are classified as hard-field when the path of the transmitting signal is in a straight line pattern. In this case, mostly the signal strength factor regarding the attenuation phenomenon of the material is measured. For soft-field tomography, the phenomena have non-linear nature and the medium distribution perturbs the transmitted signal path. This induces additional computer methods to be implemented during the image reconstruction process considering i.e. a second-order partial differential equation (Poisson's or Laplace's equation) supported with Dirichlet's and Neumann's boundary conditions.

\section{Optical sensors}

Optical tomography provides a tool for the determination of the spatial distribution of materials with a different optical density in a volume by non-intrusive measurement. The wide spectrum of light from infrared to ultraviolet can be applied. The receivers can measure the level of light beam absorption, reflection, diffraction or refraction and then reconstruct the image of components distribution. This technique was successfully applied to the flow processes in ' 80 of last century. The simple multi-angular technique which involves making light's beam absorption measurements (projections) can be read in [131] and the application of holographic interferometry in [136]. The laser-based tomography technique used for flow visualisation in supersonic ejectors was described in [20]. One of the examples of optical fibre process tomography can be found in [162]. This technique, to acquire enough projections, involves rotatable scanning. In [58], the concentration of gas bubbles in a water column was measured using an optical tomography system. Besides, a hybrid back-projection algorithm was applied to provide a tomographic image of the measurement cross-section and to calculate concentration profiles. The algorithm combined the characteristic of an optical sensor as a hard field sensor and the linear back projection algorithm. The significant disadvantage of this technique is a requirement of mounting the transparent part of the pipeline.

\section{Quantitative magnetic resonance flow imaging}

Magnetic resonance method assumes the use of radio-frequency signals. The molecular species of the examined medium are placed inside the magnetic field and in a result of excitation are changing the magnetic field frequency providing the spectral information about the organic compounds distribution and dynamic information such as diffusion and flow inside the measurement volume [29, 141].

\section{Ultrasound}

Instrumentation systems employing a variety of ultrasonic techniques have been widely applied to the industrial flow processes. The transducers mostly are composed of a set of transmitter-receiver pairs. One of the numerous examples of applications may be found in [161]. The authors designed a system involving a fan-shaped beam scanning geometry and a fast binary back-projection filtering algorithm. Kurniadi and Trisnobudi [80] proposed in their work a flow meter based on a multi-path ultrasonic transit time evaluation for velocity profile measuring of the gas flow. A set of transmitter-receiver pairs was located around the pipe wall. To reconstruct the velocity profile, the algorithm of filtered back-projection was implemented. Similarly, the same image reconstruction technique and the Ultrasound Tomography (UST) was used in [28] to imagine the flow from the line-averaged velocity distribution in Radon space. The method of ultrasonic pulse echo reflected from the pipe's internal wall is proposed in [82] for flow pattern identification in a horizontal pipe with gas-liquid TPF. Moreover, Abbagoni and Yeung [1] designed the neural network for classification of gas-liquid twophase horizontal flow regimes from ultrasonic measurement data.

\section{High energy rays tomography}

Computer Tomographic (CT) imaging technique, developed as a medical diagnostic system found its application as a tool for industrial non-destructive evaluation. This industrial brother of CT contributed to this field providing the three-dimensional inspection of defects, their location and size. In this matter, the high energy ( $\mathrm{X}$ or gamma)-ray source together with the detectors array are necessary to apply. Then, to reconstruct the cross-sectional 2D or spatial 3D high quality image the set of transmitter-receivers needs 
to be rotated or replicated. In 1999, Luggar et al. [89] designed energy-dispersive X-ray scatter for measuring oil and water concentrations in a bulk liquid. The designed system had a relative error up to $0.6 \%$ in the oil/water ratio measurement.

Ultrafast electron beam X-ray computed tomography is a powerful imaging technique for the analysis of two- and multiphase flows. In the basis of this, in work [42], a specific system was designed whereas the scanning mode the beam was circularly guided across the target to produce a rapidly moving X-ray spot. The detector had a sampling rate of up to $1 \mathrm{Msample} / \mathrm{s}$. The measurement data were processed by the algorithm based on the filtered back-projection technique and produced cross-sectional images with the maximum rate about $7 \mathrm{kHz}$. This rate was limited by the capability of the deflection coil amplifiers to adjust the required elliptical beam deflection pattern. Bieberle et al. [18] in turn implemented the method to obtain virtual 3D CT images from the two-plane measurement of a buoyancy-driven water-air flow within a packed bed. Then, the phase segmentation was performed by adequate thresholding and the phase fraction profiles as well as velocity profiles were calculated. Barthel et al. [15], using the same measurement technique, evaluated velocity profile as well. The slice images were reconstructed, with a spatial resolution of approximately $0.6 \mathrm{~mm}$ per pixel and were pre-processed by selecting a region of interest, enhancing contrast and removing background.

Many applications of high energy radiation also use gamma rays. The studies $[11,98,129]$ describe the developments of multisource gamma CT systems which proved to be useful tools to evaluate multiphase systems by volume fractions and flow regime identification. Hjertaker et al. [53] designed the multimodality sensing system for monitoring of multiphase hydrocarbon flow where there was a need to measure the quantity of oil, water and gas in a cross-section of a pipe originating from an oil well.

Multimodality tomographic systems consisted of electrical capacitance and gamma-ray sensing provide component specificity of oil/water/gas. For these purposes, the algorithm with dual-modality tomograms to three component tomogram mapping procedure needs to be implemented. The three-phase flowmeters are now becoming a demanded part of many production systems in the oil and gas (petroleum) industry. In [145], there is accomplished a comparison of commercial flowmeters, which by merging the abilities of hard-field sensing with the methods of image reconstruction and processing can meet the growing demands of applications.

\section{Electrical tomography}

Electrical Impedance Tomography (EIT) technique delivers the two- and three-dimensional imaging on the basis of electric features (permittivity, conductivity, inductivity) of the process' components e.g. flow. The first Electrical Capacitance Tomography (ECT) systems [120, 113, 158, 79], Electrical Resistance Tomography (ERT) systems [33, 32, 147, 127] as well as the Magnetic Induction (MI) $[90,119]$ allowed to obtain only the rough evaluation of the process state because the information encoded in measurement data represents merely the fragment of the process which additionally was approximated into the cross-section surface through the sensor (2D ECT) $[60,163,78,128$, 135]. This kind of imaging, however still commonly applied in many industrial applications [50, 66, 67, $104,75,65]$, occurs to be insufficient from the process control point of view. The cross-sectional image does not reflect enough the spatial phase distribution or flow structure in a measurement volume. It is because the image is generated according to the approximated measurement values from the whole electrodes surfaces. In the case of long electrodes, the high level of approximation prevents the precise measurements. Moreover, the spatial electrostatic field distribution is neglected. Therefore, the ECT monitoring was developed in the direction of other data processing methods like cross-correlation [103, 84, 87, 31], image processing and analysis, multi-layered tomography [100, 55, 154, 45] or even rotatable sensor [86] etc. Nevertheless, independently of the mentioned extensions still the classic 2D ECT measurement suffers from the limitations of the cross-sectional approximation. Many of the industrial processes are characterised by the spatial features and their reduction to the planar solution results in undesirable simplifications. One of the first efforts to produce 3D images using tomographic algorithms from 3D ERT measurements data applied to two production pressure filters can be found in $[164,114]$. Moreover, the authors implemented the dynamic sensitivity maps recalculation algorithm. The maps evolve according 
to the conductivity changes that occur in the filter during a batch. Analogously, some first 3D imaging system was designed based on ECT measurements $[96,156,150,137]$.

\section{Multimodal tomography}

Due to the complex nature of processes the power of process tomography can be multiplied to measure several physical properties. Then, data from more than one sensor are superimposed together with data from other sensors. In case of multimodal systems, lots of issues must be considered. First, the multimodal sensor, capable of detecting various properties based on differing modalities needs to be designed. Next, these different types of sensor hardware need to be combined into a single data acquisition system. Finally, a specialized reconstruction algorithm that differentiates between components needs to be implemented. Marashdeh et al. [95] designed the system of dual imaging modality (permittivity and conductivity distributions) of granular flow based on ECT sensors. Capacitance and power measurements were acquired by an ECT sensor located around the vessel and then reconstructed and presented in a form of the $2 \mathrm{D}$ cross-sectional images. The inverse problem was determined using the optimization technique based on neural network. A design of conductance and capacitance dual-modality tomography applied for flow measurements can also be read in [153, 157].

A dual-modality tomography for air bubble detection with fusion of resistance and UST was proposed in [165]. ERT sensing was influenced by air bubbles but UT, in turn, was highly influenced by interruption of the transmission path. Fusion of both techniques provides improved ability of objects detection because two different images of the same volume can be obtained simultaneously.

However, such hard-field and soft-field modalities combination is commonly encountered especially in the petroleum industry to distinguish gas, oil and water fractions. Snakowski et al. [130] patented a method and a device for measuring conductive and/or non-conductive component fractions in a flow. The designed three-phase flow meter based on combining three modalities: ECT, ERT and gamma ray radiation is able to determine the flow composition of a mixed flow in vertical and horizontal pipelines.

\section{Flows Parameters Identification}

To describe a TPF, it is usual to specify the total flow regime and to characterize the fractions that the flow consists of. A complete description of a TPF contains also the phase distribution and its velocity. In this section, the solutions for identifying the flow parameters are provided. The knowledge is divided into features categories of this phenomenon as void fraction distribution, velocity profile and flow regime.

\section{Holdup measurement and void fraction distribution}

The liquid holdup is significant parameters for TPF. In such a process, each fraction moves at a different speed. To determine the void fraction distribution and flow rates, one of the methods is to measure the holdup of flow components. In the world literature, there are presented many of solutions for liquid holdup determination. An intrusive example of the Quick Closing Valves method (QCV) is presented in $[64,57$, 49].

However, void fraction is a very important parameter in multiphase flows. The QCV method interrupts the process while the EIT allows keeping out of this undesirable effect. Hua et al. [56] measured the volume and velocity of oil fraction in vertical flow applying dual-plane ERT and dual-sensor conductance probe. To reconstruct the distribution of the flow, they adopted the algorithm of back-projection. To obtain the oil velocity, the correlation-based method was additionally applied. The presented method suffers from some limitations. The method requires some time (up to 30 seconds) to form the flow. Moreover, if the flow could not be stable enough, the method results with significant differences. A similar approach may be found in [67] where the authors designed algorithms based on a linear approximation of the sensitivity back-projection method for handling full void fraction range in two-phase flow ERT measurement with the error less than $2 \%$.

Similar high accuracy of electrical tomography has also been reported in [151]. In this work, the reader may find results of experiments on the two-phase horizontal flow that aim to compare various diagnosis techniques like QCV as a reference method, CCDbased edge detection system and 3DECT-based fuzzy logic classification. The measured void fraction dis- 
tribution together with a calculated standard deviation is depicted in Figure 3.

\section{Figure 3}

Comparison of accuracy of void fraction measurement methods [151]

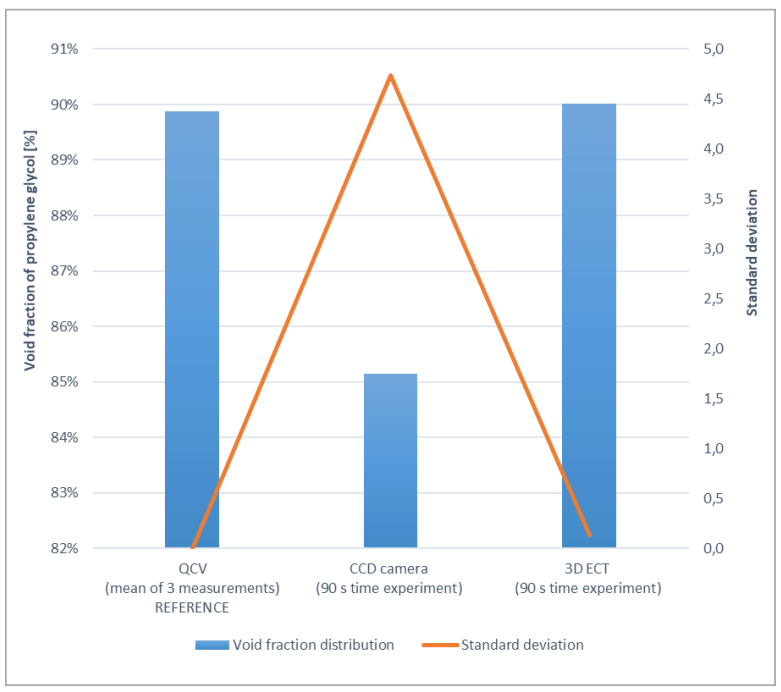

\section{Velocity profile}

The non-invasive tomographic techniques supported additionally by computer methods like tomograms processing and analysis, cross-correlation etc. designate a standard in velocimetry. The most common solutions are based on resistance and ultrasonic diagnosis. The three-path ultrasonic flow meter for fluid velocity profile identification was proposed in [62]. The ability of the first method is sensitive to the flow profile. In case of non-axisymmetric flow, the metering device has to be reinstalled. Otherwise, it indicates that the flow rate is of reduced accuracy and may be unreliable. Similar approach read in [143] can detect the Doppler shift frequency as a function of time. The authors of this method gave many examples where their solution has already been applied e.g. Flow Mapping of a Recirculating Flow in a Square Cavity, stirring and mixing processes in a hyperboloid stirrer vessel, detecting the velocity field in the vicinity of a mechanical valve substitute for simulating pulsatile flow as well as in a 10-mm pipe with raw chocolate and many others. Likewise, UST and extra convolution algorithm for parallel scan data were applied in [76] to visualise the velocity profile of air flow. In [105], the multiwave ultrasonic excitation was shown to be applied to the autocorrelation pulsed-Doppler velocity profile measurement of counter-current two-phase bubbly flow in a vertical pipe. In this case, the system is able to measure both the liquid- and bubble-velocity profiles saving the spatial resolution below $0,8 \mathrm{~mm}$. The last example of a UST velocimeter can be found in [83]. This device is capable to provide quantitative images of axial flow fields in pipes and to detect the flow in various directions and positions. The filtered back projection (FBP) algorithm has been employed to reconstruct the axial flow field. The method was validated using CFD simulation and the velocity relative error was $1,1 \%$.

Naturally, other tomography techniques are also appropriable for this task. Many of the proposed methods for velocity profile determination are based on EIT monitoring. For instance, an application of ERT for shampoo velocity measurement is presented in [121]. According to the conductivity changes the functionality of in-line rheometer was achieved on the basis of ERT technique. The further analysis of the shampoo flow velocity was also investigated. Moreover, the flowmeter which uses measurements of electrical conductance, electrical capacitance and density of the threephase mixture in the petroleum industry was designed in [145]. The cross-correlation technique was used to measure the velocities of the three phases. Similar, the cross-correlation method by using parallel-wire capacitance probe was designed in [168] to measure velocities of six flow patterns in horizontal oil-water TPF in the petroleum industry. Authors noted that the accuracy of the cross-correlation technique strongly depends on the relationship between the velocity inferred from the correlation function's peak position and the mean velocity of the flow. To overcome this issue, they predict the homogeneous velocity of oil-water TPFs upon kinematic wave model.

However, the most advanced cross-correlation-based algorithm was implemented in [103]. The authors, using reconstructed data acquired from a twin-plane ECT system, were looking for the best-correlated pixel on the second sensor plane in the neighbourhood of the corresponding pixel. This concept without the requirement of any additional assumption is not limited only to determine the velocity vector that is perpendicular to the pipe axis.

\section{Flow regime identification}

During an industrial flow process monitoring, an identifying the flow regime and determining its struc- 
tures are of great importance. It can be determined by flow patterns which can vary for different kinds of flows components i.e. gas / liquid / solid and can be organized in so-called flow maps. This map indicates the most likely flow regime for the given regime of single phase streams and is provided in many research works $[110,94,118]$. The pattern of the flow depends on many factors like flow components, pipeline (its diameter, length, position, arrangement and shape etc.), supply devices (pumps, compressors etc.). The TPF type identification task is valuable especially while designing new productions lines. It may provide knowledge about the dynamic states of the flow to control it more efficiently.

Some works have widely adopted image processing techniques. Flow images used to be captured with camera and to be pre-processed. After then, to identify flow regime some image processing algorithm such as watershed segmentation, top-hat filtering and H-minima transform etc. can be applied [146, 7$]$. The processing allows determining the bubble velocity, shape, length and frequency with the standard error of $7 \%$. In [132], the authors implemented additional post-processing based on the Artificial Neural Network (ANN) and supported vector machine. The network can reflect both the dynamic and complex characteristics of the TPF with the accuracy of 98.03. There are also solutions which are using stochastic models to model randomly changing processes. The works [91, 124, 123], to identify TPF regimes, propose methods of the on-line fluid phase signals analysis implementing hidden Markov model.

Many solutions based on artificial intelligence become more and more popular in the industrial applications. It is due to their ability to perform various tasks similarly as the humans think. The intelligent algorithms are trying to solve a problem, and then are using the outcomes of this study as a basis for their next inference. One of the most common research areas in this domain is the ANNs. In [102], the authors proposed a flow regime identification methodology with the supervised and self-organising ANN and TPF models. The ANN was used as well in [111, 36] for estimation of flow patterns and frictional pressure losses of two-phase fluids in horizontal wellbores. The ANN may support tomographic techniques by providing a mechanism for image reconstruction and analysis [74]. Figueiredo et al. [41] applied an ultra- sonic technique and ANNs to identify the flow pattern and volume of the gas fraction. ANN executes a non-linear mapping and cross-correlation of input and output signals. Similarly, in [52], the application of an ANN was designed to analyze and to classify the measurement signals of a bubbles length function obtained from the conductivity sensor. The self-organized ANN was used as the mapping system.

Another and most reliable intelligent method repeatedly applied for industrial monitoring and control purposes is fuzzy logic. Classical logic considers two states mostly given as 0 and 1 (false and true). Such an approach can e.g. handle the flow as air or liquid phases with the clear boundary between them. Fuzzy logic allows understanding the problem in a "more human" way [77]. It assumes the existence of more values or states between 0 and 1 (e.g. almost true, probably) blurring (fuzzing) the boundaries so far considered as crisp. Some works have been done to determine flow patterns using fuzzy inference on image analysis. In [99], the authors implemented image pattern classification systems based on simple features using a fuzzy inference system. The TPF regime identification system to manage heat transfer of the nuclear reactor coolant was designed in [23]. The image segmentation process was used to divide the image into sub-regions and then the fuzzy image processing was applied to detect bubbles in the natural circulation system.

Other research team performed boiling regime classification on low-resolution, low-speed images using simple machine learning and image processing techniques [54]. The classifiers ware trained on the measurement data. Both support vector machines and ANNs were able to identify pool boiling regimes with about $99 \%$ precision.

The first use of a fuzzy pattern recognition technique in basis on tomographic measurement was introduced in $[47,159]$ to solve the flow pattern identification. The images captured by the ECT system are analyzed through image processing and a pattern recognition technique. However, the fuzzy logic inference was applied for the first time to the three-dimensional reconstructed images as an efficient evaluator $[13,151]$. In this study, the two-phase vertical and horizontal flow regimes classification was obtained from spatial analysis of a set of objects from 3D reconstructed images. The developed system allowed 
the real-time non-invasive determination of the void fraction and structure identification thanks to the specialized parallelized algorithms for fast processing of measured data. The implementation of forward and inverse problem computations was done using CUDA technology.

\section{Imaging or not imaging?}

Most of the research works based on the tomographic techniques have implemented the image reconstruction methods. In many industrial applications supported by the tomographic diagnosis, beside the accurate measurement devices the key role plays the data processing and image reconstruction methods. From these methods, it is expected the high image quality together with the short processing time. These challenges concern the essential computer issues like the image resolution enhancement saving quality and processing time what definitely results in the computation complexity, computer modelling of measurement sensors, numerical errors and finally in the necessity of development of new algorithms for efficient management of resources as well as computation power. If the image is especially important for the issue of monitoring and visualization, the image reconstruction and processing tasks can be performed on graphical processors. Kapusta et al. [70] developed an effective method called a General Purpose computing on Graphics Processing Units that involves a hybrid algorithm for rapid, parallel determination of the solution of forward problem implementing CUDA API and OpenCL libraries by uses of both x86/x64 class and graphics processors.

How significantly efficient the parallel computing is, it can be read in the work [92] where authors described expedients while under the same conditions they performed 100 iterations of the Landweber's image reconstruction algorithm for ECT. The processing was executed on various computational platforms ones based only on CPU and next on 1 and 4 GPUs. As can be seen in Figure 4, the total computational time was reduced even up to $0,8 \%$ for the densest mesh.

There are some researches that perform direct flow-pattern identification from measurement data. In [65], the general idea for flow-pattern classification relied on the finding of geometrical properties hidden in a measurement frame corresponding to a set of

\section{Figure 4}

100 iterations of the image reconstruction algorithm for ECT executed under the same conditions on various computational platforms [92]

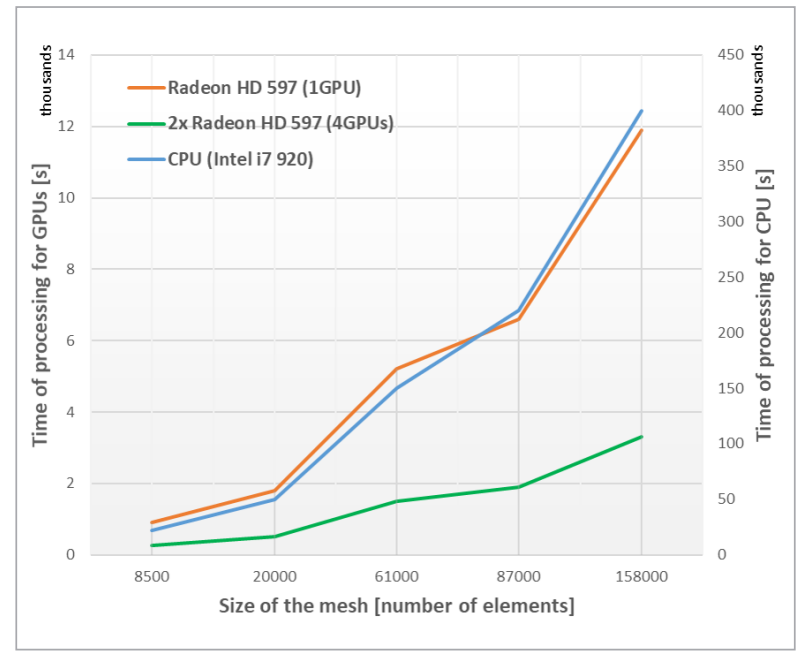

ECT measurements without the need of imaging. The decision was made on the basis of one frame only to ensure the process to be as quick as possible. A similar approach was studied in [122] where to develop a new strategy for flow systems monitoring the contextual processing of the ECT measurements data was implemented. The signal processing refers to methods and algorithms taking advantage over classical approaches by using context-aware, context-enabled or context-driven features in order to enhance computer systems or applications.

The analysis of the tomographic raw measurement data for TPF type identification is actually more effective (not only in terms of processing time). The methods based on the 3D reconstructed images analysis [13] gave mostly satisfying results but because of its lower speed there is a risk to miss (not detect) some specific features of the dynamic flow such as plugs or foam which are important to recognize the current type of the flow. The same group of researchers in [40] designed a fuzzy logic based method for 3D ECT raw measurement data processing dedicated for the identification task of the dynamic TPF processes ensuring the accuracy as good as the human expert work. It was proven that this solution is a sufficient alternative to the methods commonly used in this field and stands out with its effectiveness, low recognition time and full scalability. 


\section{Flow Control}

The task of flow control is of substantial meaning in any branch of industry where these processes are used for production, transport etc. Because of the applications' variety in each case the needs and demands are different. Nevertheless, the important thing is to keep the flow regime on the given level or to avoid of e.g. slugs' occurrences. Severe slugging may have undesirable effects on the many processes causing problems including unstable pressure, kinetic force or insufficient phase separation. In case of too large slugs the pipeline flooding or damage is possible. That is why the highly important is to identify the slugs and to determine their frequency, size and velocity.

However, in case of such dynamic, stochastic and non-linear processes like flows one needs to be remembered: holding the same level of phases' streams supply does not guarantee the flow regime stability [142]. Therefore, there is a necessity to process the continued monitoring and to immediately react in case of any abnormalities. In the world literature, many research works may be found which, using various modelling techniques, provide the tools for control process simulation or even for threats estimation. The example showing the control task's complexity is the mathematical flow control scheme introduced in [3] to minimize the turbulences in the basis of four different models. Next, in [17], the readers may find out the discussion on the interdisciplinarity of the algorithms development process for flow control purposes issuing requirements and limitations while working out the optimality of this task in the context of different applications. Furthermore, some problems in the flow modelling and control in the basis of the flow pattern and flow map using the specified Eötvös number classification have been demonstrated in [21]. Havre and Dalsmo [51] deal with the results from simulations with the feedback flow control which show how to avoid slugs and hold on the stable conditions both at the pipeline inlet and outlet, whereas without control severe slug flow was experienced. In [134] in turn, the authors made the exhaustive analysis on control models commonly used by industrial control engineers. The discussion about the advantages as well as the limitations of the single input single output (SISO) in contrast to the multi-input multi-output (MIMO) feedback control systems may be found. The case study on the controllability prop- erties of a typical pipeline-riser system of two fluid flow with the PDE-based (partial differential equations) model was described in [140].

Besides the theoretical achievements, some works have been performed to design the feedback control solutions based on PID [44,117, 4] or PI [107] controllers to demonstrate that this strategy can guarantee the stability of the flows whereas the manual choking occurred insufficiently. The production (subsea) choke is used to control the offshore flow and stabilize the flow line pressure. The controllers mostly measure the bottom-hole and top pressure. The authors noted that to avoid riser slugging a strategy to control the pure inlet pressure for pipelines with limited length is most recommended. Otherwise, more advanced cascade controller should be employed combing e.g. flow line pressure and volumetric flow control. Many of functional examples may be found in [44].

Also in [108] the auto-tuned PI controller algorithm based on a perturbed First-Order-Plus Dead-Time (FOPDT) delay model of the riser system was introduced which was developed and implemented for severe slugging control focusing on achieving stable operation and maximizing production. The author indicates that the solution has the ability to stabilize the unstable riser system at a valve opening that is larger than that achieved with the original (conventional) controller algorithm. Moreover, the linearization closed in a feedback loop in a combination of pressure drop was used in [63] for the control design of the production choke valve to prevent severe slugging flow conditions. Thanks to the authors' solution it was possible to successfully maintain the stability of large valve opening in the experimental rig without the need of re-adjusting it. Nevertheless, Di Meglio et al. [97] analyzed the disadvantages of the production choke control system based on non-collocated PI-controller in contexts of their new approach of the nonlinear state-feedback control law based on a first principles model of the slugging phenomenon. In this case, only one parameter (the gas pressure) was adjusted. Elsewhere, the detailed analysis and the discussion about the problems and optimization of the linear controllers were performed in [73] and especially in case of slug attenuation in [35]. Generally, after studying the referred works one conclusion may be drawn. Due to the complexity of the flow processes (especially severe slug flows in offshore 
multiphase oil \& gas pipeline transportation systems), the design of the robust control system based on an active feedback control makes a major challenge to achieve the desired performance and optimal efficiency [126].

What is more, for the non-linear systems such as flow processes, PID controllers do not exhibit good performance. Therefore, in order to satisfy the need for system stability and to optimize production simultaneously some other solutions for flow control were developed. The comprehensive review study of non-linear controller theory together with some examples may be found in [59]. Authors deal with the differential algebra and multivariable calculus to explain the mathematical basis of nonlinear controllers.

Another computer technique which may successfully compete with the linearized feedback systems is fuzzy inference. The fuzzy controllers surely belong to the group of predictive controllers and have already been applied many times including scheduling and controlling electrical operators [27], the maintenance a floating level in a tank on top of the atmospheric distillation unit of the refinery [43] or the boiling water reactor as a recirculation flow control system [10]. The usage of artificial intelligence in the industrial applications allows avoiding any random errors as well as breakdowns and human mistakes which suffer from a lack of objectivity. To know the differences between the PID and fuzzy controllers, some research works as comparative studies have been done like [24] or [116]. In both cases, the PID controllers were characterised with the slower response time also with the tendency of oscillating convergence. Much more advantages of fuzzy controllers may be found in [115]. The contributors of this work simulated fuzzy and neuro-fuzzy controllers to obtain better performance in flow process regulation in comparison to the PID. Likewise, to overcome the occurrences of unpredictable disturbances from PID regulators AL-Qutami and Ibrahim [6] designed the fuzzy controller for flow application in tanks. It can be read here that this type of controller is flexible and can handle any sudden changes or disturbances on the system and can overcome the presence of process nonlinearities, operation variability and measurements noise.

Despite many examples for fuzzy logic controllers each time the systems are dedicated for specific applications. A lot of work always needs to be per- formed to adjust such controller to the process conditions. In [39], the intelligent system for the TPFs monitoring and control on the basis of raw 3D ECT data was developed. In a frame of this study, the universal approach of the fuzzy logic controller is described that is characterised by the easy adaptation to the work conditions by the maintenance staff of the flow rig what is guaranteed in the result of sharing the individual sets of parameters and the intuitive inference rules.

The control module works in a feedback loop and keeps the sets of required flow regime. In the inference process, it considers not only the current flow type and the flow type set by the user but also the current state of the flow rig (i.e. the current values of the control signal). It is possible to change the TPF type changing only one control parameter about the minimum value which is required to achieve the set flow type and simultaneously without excessive overcharging the flow rig and the supply units. This approach allows the user of the system to avoid looping over in case when the algorithm would try to reach the unsupported or undesirable flow type. It is not required to determine any of complicated computer models of the flow rig, what is unfortunately necessary when using the classic regulators.

An additional feature of this system is the universal mobile multi-touched monitoring-control panel which gives the opportunity to build a user-own virtual model of the flow rig to monitor and control the process efficiently.

\section{Conclusions and Future Directions}

The advanced industrial processes automation and control play the key role in competitiveness enhancement. If expensive technical devices and production lines mean the heart of the industrial production, the control systems and information technologies will become their brain. They ensure the flexibility in case of their fast adaptation to any industrial processes taking into account the volatile demands and provide the safety and efficiency respecting sustainable consumption of energy and resources. Therefore, the development of advanced process control is one of the most important challenges for instant and long-term energy saving, quality improvement. Finally, it guides 
to the economic growth in conventional and new industrial areas.

Nowadays, the meaningful progress in massive parallel computational systems enables the real-time data processing additionally distributed among the external environments (i.e. clouds). Therefore, now the process tomography, known so far only from its significant computational complexity, has the opportunity to be the demanded powerful multi-sensor technique. This conception, of course, still requires new data processing strategies to be developed.

Similar, the immeasurable capabilities are hidden in distributed systems. The cited works (both for diagnosis and control purposes) which involved the methods based on artificial intelligence (e.g. ANN, fuzzy inference) dealt with aspects from computational intelligence theory. A very attractive and innovative issue would be applications on swarm intelligence. The significant improvement in accuracy (highly demanded in case of process diagnosis) together with the increase of efficiency would be expected. Such solutions could comprise the convolutional ANNs or various algorithms of deep learning as well [37].

Finally, we cannot forget that we are living in a world of the fourth industrial revolution. The new trends and technologies are developed extremely fast and the ongoing barrier between human and the machine disappears. This revolution is accelerated by the development of Internet of Things (IoT) conception,

\section{References}

1. Abbagoni, B. M., Yeung, H. Non-invasive Classification of Gas-Liquid Two-phase Horizontal Flow Regimes Using an Ultrasonic Doppler Sensor and a Neural Network. Measurement Science and Technology, 2016, 27, 084002. https://doi.org/10.1088/0957$0233 / 27 / 8 / 084002$

2. Abdulmouti, H. Bubbly Two-phase Flow: Part II- Characteristics and Parameters. American Journal of Fluid Dynamics, 2015, 4, 115-180. https://doi.org/10.5923/j. ajfd.20140404.01

3. Abergel, F., Temam, R. On Some Control Problems in Fluid Mechanics. Theoretical and Computational Fluid Dynamics, 1990, 1, 303-325. https://doi.org/10.1007/ BF00271794 mobile 5G communication, big data and cloud computing. This leads us to integration with the diagnostic and control systems in basis of the wide usage of internet's resources. Industry 4.0 surely would not discount the TFP processes, which often take place under the inaccessible and dangerous conditions and therefore would gain them in new technologies based in computer methods, artificial intelligence and distributed processing listed in this review. Reading this work provides with not only the fundamental insight into the existing solutions for TFP diagnosis and control techniques but also with the future directions in the context of innovative information technologies applications. The given state-of-the-art as well as the new development trends make this review as a valuable resource for engineers and young researchers who start dealing with TFP processes.

\section{Acknowledgements}

Author wants to thank Prof. Dominik Sankowski, Prof. Jacek Kucharski, Robert Banasiak, Paweł Fiderek, Tomasz Jaworski and Jacek Nowakowski for support and their fruitful advices.

This work was financed by the Lodz University of Technology, Faculty of Electrical, Electronic, Computer and Control Engineering as a part of statutory project No. 501/12-24-2-5416 and by The Polish National Centre for Research and Development - project no. POIR.04.01.02-00-0089/17-00.

4. Ajwad, S., I. Ullah, M., Baizid, K., Iqbal, J. A Comprehensive State-of-the-Art on Control of industrial Articulated Robots. Journal of the Balkan Tribological Association, 2014, 20, 499-521. https://doi.org/doi. org/10.1515/nleng-2016-0077

5. Akita, K., Okazaki, T., Koyama, H. Gas Holdups and Friction Factors of gas-Liquid Two-phase Flow in an Airlift Bubble Column. Journal of Chemical Engineering of Japan, The Society of Chemical Engineers, Japan, 1988, 21, 476-482. https://doi.org/10.1252/jcej.21.476

6. AL-Qutami, T. A. H., Ibrahim, R. Design of a Fuzzy Logic Process Controller for flow Applications and Implementation in Series Tanks Pilot Plant. 2015 International Conference on Industrial Instrumentation 
and Control (ICIC), IEEE, 2015, 450-455. https://doi. org/10.1109/IIC.2015.7150784

7. Amaral, D. C. E. F., Alves, R. F., da Silva, M. J., Arruda, L. V. R., Dorini, L., Morales, R. E. M., Pipa, D. R. Image Processing Techniques for high-Speed Videometry in Horizontal Two-phase Slug Flows. Flow Measurement and Instrumentation, 2013, 33, 257-64.https://doi.org/10.1016/j.flowmeasinst.2013.07.006

8. An, Z., Ningde, J., Lusheng, Z., Zhongke, G. Liquid Holdup Measurement in Horizontal Oil-Water Two-phase Flow by Using Concave Capacitance Sensor. Measurement, 2014, 49, 153-163. https://doi.org/10.1016/j.measurement.2013.11.036

9. Anderson, J. D. Computational Fluid Dynamics: The Basics With Applications [Internet]. McGraw-Hill Science/Engineering/Math, 1995.

10. Arakawa, A., Sekimizu, K., Sumida, S. Fuzzy Logic Control Application for BWR Recirculation Flow Control System. Journal of Nuclear Science and Technology, 1988, 25, 263-273. https://doi.org/10.1080/18811248.1 988.9733586

11. Arvoh, B. K., Hoffmann, R., Halstensen, M. Estimation of volume Fractions and Flow Regime Identification in Multiphase Flow based on Gamma Measurements and Multivariate Calibration. Flow Measurement and Instrumentation, 2012, 23, 56-65. https://doi.org/10.1016/j.flowmeasinst.2011.11.002

12. Balamurugan, S., Lad, M. D., Gaikar, V. G., Patwardhan, A. W. Hydrodynamics and Mass Transfer Characteristics of Gas-Liquid Ejectors. Chemical Engineering Journal, 2007, 131, 83-103. https://doi.org/10.1016/j. cej.2006.12.026

13. Banasiak, R., Wajman, R., Jaworski, T., Fiderek, P., Fidos, H., Nowakowski, J., Sankowski, D. Study on Two-phase Flow Regime Visualization and Identification Using 3D Electrical Capacitance Tomography and Fuzzy-Logic Classification. International Journal of Multiphase Flow, 2014, 58, 1-14. https://doi.org/10.1016/j.ijmultiphaseflow.2013.07.003

14. Banasiak, R., Wajman, R., Sankowski, D., Soleimani, M. Three-Dimensional Nonlinear Inversion of Electrical Capacitance Tomography Data Using a Complete Sensor Model. Progress In Electromagnetics Research Pier, 2010, 100, 219-234. https://oi.org/10.2528/ PIER09111201

15. Barthel, F., Bieberle, M., Hoppe, D., Banowski, M., Hampel, U. Velocity MEASUrement for Two-phase Flows Based on Ultrafast X-ray Tomography. Flow Measure- ment and Instrumentation, 2015, 46, 196-203. https:// doi.org/10.1016/j.flowmeasinst.2015.06.006

16. Beux, S., Nunes, E., Barana, A. C. Effect of Temperature on Two-phase Anaerobic Reactors Treating Slaughterhouse Wastewater. Brazilian Archives of Biology and Technology, 2007, 50, 1061-1072. https://doi. org/10.1590/S1516-89132007000700017

17. Bewley, T. R. Flow Control: New Challenges for a New Renaissance. Progress in Aerospace Sciences, 2001, 37, 21-58. https://doi.org/10.1016/S0376-0421(00)00016-6

18. Bieberle, M., Barthel, F., Hoppe, D., Banowski, M., Wagner, M., Lucas, D, Stürzel, T., Hampel, U. Ultrafast Electron Beam X-ray Computed Tomography for 2D and 3D Two-phase Flow Imaging. 2012 IEEE International Conference on Imaging Systems and Techniques Proceedings, IEEE, 2012, 605-610. https://doi. org/10.1109/IST.2012.6295548

19. Blažej, M., Cartland Glover, G. M., Generalis, S. C., Markoš, J. Gas-Liquid Simulation of an Airlift Bubble Column Reactor. Chemical Engineering and Processing: Process Intensification, 2004, 43, 137-144. https://doi. org/10.1016/S0255-2701(03)00010-2

20. Bouhanguel, A., Desevaux, P., Gavignet, E. Flow Visualization in Supersonic Ejectors Using Laser Tomography Techniques. International Journal of Refrigeration, 2011, 34, 1633-40. https://doi.org/10.1016/j. ijrefrig.2010.08.017

21. Brauner, N. Liquid-Liquid Two-phase Flow Systems. In: Bertola, V. (Ed.), Modelling and Control of Two-phase Phenomena, CISM Center, Udine, Italy, 2002. https://doi.org/10.1007/978-3-7091-2538-0_5

22. Brebbia, C. A., Mammol, A. A. Computational Methods in Multiphase Flow VI. 2011.

23. Bueno, R. C., Masotti, P. H. F., Justo, J. F., Andrade, D. A., Rocha, M.S., Torres, W. M., de Mesquita, R. N. Two-phase Flow Bubble Detection Method Applied to Natural Circulation System Using Fuzzy Image Processing. Nuclear Engineering and Design, 2018, 335, 255-264. https://doi.org/10.1016/j.nucengdes.2018.05.026

24. Chandan, S., Agnihotri, R. Fuzzy Logic Controller for Flowing Fluids. International Journal of Advanced Research in Computer Engineering \& Technology, 2012, 1, 98-101.

25. Chen, J., Wang, Y., Zhang, W., Qiu, L. Zhang, X. Capacitance-Based Liquid Holdup Measurement of Cryogenic Two-phase Flow in a Nearly-horizontal Tube. Cryogenics, 2017, 84, 69-75. https://doi.org/10.1016/j. cryogenics.2017.04.006 
26. Cheng, L., Ribatski, G., Thome, J. R. Two-phase Flow Patterns and Flow-Pattern Maps: Fundamentals and Applications. Applied Mechanics Reviews, American Society of Mechanical Engineers, 2008, 61, 050802. https://doi.org/10.1115/1.2955990

27. Cheng, S.-T., Chou, J.-H. Fuzzy Control to Improve Energy-Economizing in Cyber-Physical Systems. Applied Artificial Intelligence, 2016, 30, 1-15. https:// doi.org/10.1080/08839514.2015.1121065

28. Chun, S., Yoon, B.-R., Lee, K.-B. Diagnostic Flow Metering Using Ultrasound Tomography. Journal of Mechanical Science and Technology, Korean Society of Mechanical Engineers, 2011, 25, 1475-1482. https://doi. org/10.1007/s12206-011-0405-0

29. d'Avila, M. A., Powell, R. L., Phillips, R. J., Shapley, N. C., Walton, J. H., Dungan, S. R. Magnetic Resonance Imaging (MRI): A Technique to Study Flow an Microstructure of Concentrated Emulsions. Brazilian Journal of Chemical Engineering, Associação Brasileira de Engenharia Química, 2005, 22, 49-60. https://doi. org/10.1590/S0104-66322005000100006

30. Delnoij, E., Kuipers, J. A., van Swaaij, W. P., Westerweel, J. Measurement of Gas-Liquid Two-phase Flow in Bubble Columns Using Ensemble Correlation PIV. Chemical Engineering Science, 2000, 55, 3385-3395. https://doi.org/10.1016/S0009-2509(99)00595-3

31. Deng, X., Dong, F., Xu, L. J., Liu, X. P., Xu, L. A. The Design of a Dual-plane ERT System for Cross Correlation Measurement of Bubbly Gas/Liquid Pipe Flow. Measurement Science and Technology, 2001, 12, 1024-1031. https://doi.org/10.1088/0957-0233/12/8/306

32. Dong, F., Zhao, G. X., Xu, L. A. Application of ERT to Measurement Gas Fraction of Two-phase Flow. Journal of East-North University, 2000, 21, 169-172.

33. Dyakowski, T., Jeanmeure, L. F. C., Jaworski, A. J. Applications of Electrical Tomography for Gas-Solids and Liquid-Solids Flows - A Review. Powder Technology, 2000, 112, 174-192. https://doi.org/10.1016/S00325910(00)00292-8

34. Dziubinski, M., Fidos, H., Sosno, M. The Flow Pattern Map of a Two-phase Non-Newtonian Liquid-Gas Flow in the Vertical Pipe. International Journal of Multiphase Flow, 2004, 30, 551-563. https://doi.org/10.1016/j. ijmultiphaseflow.2004.04.005

35. Ehinmowo, A. B., Cao, Y. Stability Analysis of Slug Flow Control. Systems Science \& Control Engineering, 2016, 4, 183-191. https://doi.org/10.1080/21642583.2016.121 3189
36. Ettehadi Osgouei, R., Ozbayoglu, M. E., Ozbayoglu, M. A.,Yuksel, E. Flow Pattern Identification of GasLiquid Flow Through Horizontal Annular Geometries. SPE Oil and Gas India Conference and Exhibition, Society of Petroleum Engineers, 2010. https://doi.org/10.2118/129123-MS

37. Ezzatabadipour, M., Singh, P., Robinson, M. D., Guillen-Rondon, P., Torres, C. Deep Learning as a Tool to Predict Flow Patterns in Two-phase Flow. In: Jorge, A., Larrazabal, G., Guillen, P., Lopes, R. L. (Eds.), Proceedings of the Workshop on Data Mining for Oil and Gas (DM4OG), Houston, Texas, USA, April 29th, 2017, 1-6.

38. Fan, D., Li-De, F., Hong-Lian, L., Yan, Z. Characterization of gas-Liquid Two-phase Flow Pattern Based on Complexity measures Analysis. 2012 International Conference on Machine Learning and Cybernetics, IEEE, 2012, 996-1000. https://doi.org/10.1109/ ICMLC.2012.6359490

39. Fiderek, P., Jaworski, T., Banasiak, R., Nowakowski, J., Kucharski, J., Wajman, R. Intelligent System for the Two-phase Flows Diagnosis and Control on the Basis of Raw 3DECT Data. Informatics Control Measurement in Economy and Environment Protection, 2017, 7, 17-23. https://doi.org/10.5604/01.3001.0010.4576

40. Fiderek, P., Kucharski, J., Wajman, R. Fuzzy Inference for Two-phase Gas-Liquid Flow Type Evaluation Based on Raw 3D ECT Measurement Data. Flow Measurement and Instrumentation, 2017, 54, 88-96. https:// doi.org/10.1016/j.flowmeasinst.2016.12.010

41. Figueiredo, M. M. F., Goncalves, J. L., Nakashima, A. M.V., Fileti, A. M. F., Carvalho, R. D. M. The Use of an Ultrasonic Technique and Neural Networks for Identification of the Flow Pattern and Measurement of the Gas Volume Fraction in Multiphase Flows. Experimental Thermal and Fluid Science, 2016, 70, 29-50. https://doi. org/10.1016/j.expthermflusci.2015.08.010

42. Fischer, F., Hampel, U. Ultra Fast Electron Beam X-ray Computed Tomography for Two-phase Flow Measurement. Nuclear Engineering and Design, 2010, 240, 22542259. https://doi.org/10.1016/j.nucengdes.2009.11.016

43. Galichet, S., Foulloy, L., Chebre, M., Beauchene, J. P. Fuzzy Logic Control of a Floating Level in a Refinery Tank. Proceedings of 1994 IEEE 3rd International Fuzzy Systems Conference, IEEE, 1994, 1538-1542. https://doi.org/10.1109/FUZZY.1994.343923

44. Godhavn, J.-M., Fard, M. P., Fuchs, P. H. New Slug Control Strategies, Tuning Rules and Experimental Results. Journal of Process Control, 2005, 15, 547-55\%. https://doi.org/10.1016/j.jprocont.2004.10.003 
45. Grudzien, K., Chaniecki, Z., Romanowski, A., Sankowski, D., Nowakowski, J., Niedostatkiewicz, M. Application of Twin-Plane ECT Sensor for Identification of the Internal Imperfections Inside Concrete Beams. 2016 IEEE International Instrumentation and Measurement Technology Conference Proceedings, IEEE, 2016, 1-6. https://doi.org/10.1109/I2MTC.2016.7520512

46. Guo, X., Zhou, X., Chen, Q., Liu, J. Flow Field and Dissolved Oxygen Distributions in the Outer Channel of the Orbal Oxidation Ditch by Monitor and CFD Simulation. Journal of Environmental Sciences (China), 2013, 25, 645-651.https://doi.org/10.1016/S10010742(12)60114-4

47. Haifeng, J., Zhiya, H., Baoliang, W., Haiqing, L. Monitoring System of Gas-Liquid Two-phase Flow. Proceedings of the 21st IEEE Instrumentation and Measurement Technology Conference (IEEE Cat No04CH37510), IEEE, 2004, 2298-301. https://doi. org/10.1109/IMTC.2004.1351552

48. Hamidi, M. J., Karimi, H., Boostani, M. Flow Patterns and Heat Transfer of Oil-Water Two-phase Upward Flow in Vertical Pipe. International Journal of Thermal Sciences, 2018, 127, 173-180. https://doi.org/10.1016/j. ijthermalsci.2018.01.020

49. Han, Y. F., Jin, N. D., Zhai, L. S., Zhang, H. X., Ren, Y. Y. Flow Pattern and Holdup Phenomena of Low Velocity Oil-Water Flows in a Vertical Upward Small Diameter Pipe. Journal of Petroleum Science and Engineering, 2017, 159, 387-408. https://doi.org/10.1016/j. petrol.2017.09.052

50. Hashemi, N., Ein-Mozaffari, F., Upreti, S. R., Hwang, D. K. Analysis of Power Consumption and Gas Holdup Distribution for an Aerated Reactor Equipped with a Coaxial Mixer: Novel Correlations for the Gas Flow Number and Gassed Power. Chemical Engineering Science, 2016, 151, 25-35. https://doi.org/10.1016/j. ces.2016.05.003

51. Havre, K., Dalsmo, M. Active Feedback Control as a Solution to Severe Slugging. SPE Production \& Facilities, Society of Petroleum Engineers, 2002, 17, 138-148. https://doi.org/10.2118/79252-PA

52. Hernández, L., Enrique Julia, J., Ozar, B., Hibiki, T., Ishii, M. Flow Regime Identification in Boiling Two-phase Flow in a Vertical Annulus. Journal of Fluids Engineering, American Society of Mechanical Engineers, 2011, 133, 091304. https://doi.org/10.1115/1.4004838

53. Hjertaker, B. T., Tjugum, S.-A., Hammer, E. A., Johansen, G.A. Multimodality Tomography for Multipha- se Hydrocarbon flow Measurements. IEEE Sensors Journal, 2005, 5, 153-160. https://doi.org/10.1109/ JSEN.2005.843903

54. Hobold, G. M., da Silva, A. K. Machine Learning Classification of Boiling Regimes with Low Speed, Direct and Indirect Visualization. International Journal of Heat and Mass Transfer, 2018, 125, 1296-1309. https://doi. org/10.1016/j.ijheatmasstransfer.2018.04.156

55. Holder, D. S. Electrical Impedance Tomography: Methods, History and Applications. CRC Press, 2004. https://doi.org/10.1118/1.1995712

56. Hua, L., Mi, W., Ying-xiang, W., Yi-Xin, M., Richard, W. Measurement of Oil Volume Fraction and Velocity Distributions in Vertical Oil-in-Water Flows Using ERT and a Local Probe. Journal of Zhejiang University-SCIENCE A, 2005, 6, 1412-1415. https://doi.org/10.1631/ jzus.2005.A1412

57. Huang, S.-F., Zhang, X.-G., Wang, D., Lin, Z.-H. Water Holdup Measurement in Kerosene-Water Two-phase Flows. Measurement Science and Technology, 2007, 18, 3784-3794. https://doi.org/10.1088/09570233/18/12/013

58. Ibrahim, S., Yunus, M. A. M., Green, R. G., Dutton, K. Concentration Measurements of Bubbles in a Water Column Using an Optical Tomography System. ISA Transactions, 2012, 51, 821-826. https://doi.or$\mathrm{g} / 10.1016 / \mathrm{j}$.isatra.2012.04.010

59. Iqbal, J., Ullah, M., Khan, S. G., Khelifa, B., Ćuković, S. Nonlinear Control Systems - A Brief Overview of Historical and Recent Advances. Nonlinear Engineering, 2017, 6, 301-312. https://doi.org/10.1515/nleng-2016-00'77

60. Isaksen, Ø. A Review of Reconstruction Techniques for Capacitance Tomography. Measurement Science and Technology, 1996, 7, 325-337. https://doi. org/10.1088/0957-0233/7/3/013

61. Izwan Ismail, A. S., Ismail, I., Zoveidavianpoor, M., Mohsin, R., Piroozian, A., Misnan, M. S., Sariman, M. Z. Experimental Investigation of Oil-Water Two-phase Flow in Horizontal Pipes: Pressure Losses, Liquid Holdup and Flow Patterns. Journal of Petroleum Science and Engineering, 2015, 127, 409-420. https://doi. org/10.1016/j.petrol.2015.01.038

62. Jackson, G. A., Gibson, J. R., Holmes, R. A Three-path Ultrasonic Flow Meter with Fluid Velocity Profile Identification. Measurement Science and Technology, 1991, 2, 635-642. https://doi.org/10.1088/0957-0233/2/77/010

63. Jahanshahi, E., Skogestad, S., Grøtli, E. I. Nonlinear Model-based Control of Two-phase Flow in Risers by 
Feedback Linearization. IFAC Proceedings Volumes (IFAC-PapersOnline), 2013, 9, 301-306. https://doi.org/10.3182/20130904-3-FR-2041.00041

64. Jana, A. K., Ghoshal, P., Das, G., Das, P. K. An Analysis of Pressure Drop and Holdup for Liquid-Liquid Upflow Through Vertical Pipes. Chemical Engineering \& Technology, 2007, 30, 920-925. https://doi.org/10.1002/ ceat.200700033

65. Jeanmeure, L. F., Dyakowski, T., Zimmerman, W.B., Clark, W. Direct Flow-pattern Identification Using Electrical Capacitance Tomography. Experimental Thermal and Fluid Science, 2002, 26, 763-773. https:// doi.org/10.1016/S0894-17r77(02)00186-3

66. Jia, J., Faraj, Y., Wang, Q. Online Conductivity Calibration Methods for EIT Gas/Oil in Water Flow Measurement. Flow Measurement and Instrumentation, 2015, 46, 213-21\%. https://doi.org/10.1016/j.flowmeasinst.2015.07.002

67. Jia, J., Wang, M., Faraj, Y. Evaluation of EIT Systems and Algorithms for Handling Full Void Fraction Range in Two-phase Flow Measurement. Measurement Science and Technology, 2015, 26, 015305. https://doi. org/10.1088/0957-0233/26/1/015305

68. Jothiprakash, V., Bhosekar, V. V., Deolalikar, P. B. Flow Characteristics of Orifice Spillway Aerator: Numerical Model Studies. ISH Journal of Hydraulic Engineering, 2015, 21, 216-230. https://doi.org/10.1080/09715010.2 015.1007093

69. Kačeniauskas, A. Solution and Analysis of CFD Applications by Using Grid Infrastructure. Information Technology and Control, 2010, 39, 284-290. https://doi. org/10.5755/j01.itc.39.4.12383

70. Kapusta, P., Majchrowicz, M., Sankowski, D., Banasiak, R. Application of GPU Parallel Computing for Acceleration of Finite Element Method Based 3D Reconstruction Algorithms in Electrical Capacitance Tomography. Image Processing \& Communications, 2012, 17, 339-346. https://doi.org/10.2478/v10248-012-0063-6

71. Kassab, S. Z., Kandil, H. A., Warda, H. A., Ahmed, W. H. Air-lift Pumps Characteristics Under Two-phase Flow Conditions. International Journal of Heat and Fluid Flow, 2009, 30, 88-98. https://doi.org/10.1016/j.ijheatfluidflow.2008.09.002

72. Kiambi, S. L., Kiriamiti, H. K., Kumar, A. Characterization of Two Phase Flows in Chemical Engineering Reactors. Flow Measurement and Instrumentation, 2011, 22, 265-271. https://doi.org/10.1016/j.flowmeasinst.2011.03.006
73. Kim, J., Bewley, T. R. A Linear Systems Approach to Flow Control. Annual Review of Fluid Mechanics, 2007, 39, 383-417. https://doi.org/10.1146/annurev. fluid.39.050905.110153

74. Kłosowski, G., Rymarczyk, T. Using Neural Networks and Deep Learning Algorithms in Electrical Impedance Tomography. Informatics Control Measurement in Economy and Environment Protection, 2017, 7, 99-102. https://doi.org/10.5604/01.3001.0010.5226

75. Kok Seong, C., Pusppanathan, J., Abdul Rahim, R., Chiew Loon, G., Susiapan, Y. S.-L., Aliah Phang, F., Rahiman, M. H. F. Hardware Development of Electrical Capacitance Tomography (ECT) System with Capacitance Sensor for Liquid Measurements. Jurnal Teknologi, 2015, 73(6), 13-22. https://doi.org/10.11113/jt.v73.4399

76. Komiya, K.-I., Teerawatanachai, S. Ultrasonic Tomography for Visualizing the Velocity Profile of Air Flow. Flow Measurement and Instrumentation, 1993, 4, 6165. https://doi.org/10.1016/0955-5986(93)90014-A

77. Kosinski, T., Obaid, M., Wozniak, P. W., Fjeld, M., Kucharski, J. A Fuzzy Data-Based Model for Human-Robot Proxemics. 2016 25th IEEE International Symposium on Robot and Human Interactive Communication (RO-MAN), IEEE, 2016, 335-340. https://doi. org/10.1109/ROMAN.2016.7745152

78. Kryszyn, J., Smolik, W. T., Radzik, B., Olszewski, T., Szabatin, R. Switchless Charge-Discharge Circuit for Electrical Capacitance Tomography. Measurement Science and Technology, IOP Publishing, 2014, 25, 115009. https://doi.org/10.1088/0957-0233/25/11/115009

79. Kryszyn, J., Wróblewski, P., Stosio, M., Wanta, D., Olszewski, T., Smolik, W. T. Architecture of EVT4 Data Acquisition System for Electrical Capacitance Tomography. Measurement, 2017, 101, 28-39. https://doi.org/10.1016/j.measurement.2017.01.020

80. Kurniadi, D., Trisnobudi, A. A Multi-Path Ultrasonic Transit Time Flow Meter Using a Tomography Method for Gas Flow Velocity Profile Measurement. Particle \& Particle Systems Characterization, Wiley-Blackwell, 2006, 23, 330-338. https://doi.org/10.1002/ ppsc.200601067

81. Lafmejani, S. S., Olesen, A. C., Kær, S. K. VOF Modelling of Gas-Liquid Flow in PEM Water Electrolysis Cell Micro-Channels. International Journal of Hydrogen Energy, 2017, 42(26), 16333-16344. https://doi.org/10.1016/j.ijhydene.2017.05.079

82. Liang, F., Zheng, H., Yu, H., Sun, Y. Gas-Liquid Two-phase Flow Pattern Identification by Ultrasonic 
Echoes Reflected from the Inner Wall of a Pipe. Measurement Science and Technology, IOP Publishing, 2016, 27, 035304. https://doi.org/10.1088/09570233/27/3/035304

83. Liu, J.-N., Wang, B.-X., Cui, Y.-Y., Wang, H.-Y. Ultrasonic Tomographic Velocimeter for Visualization of Axial Flow Fields in Pipes. Flow Measurement and Instrumentation, 2015, 41, 57-66. https://doi.org/10.1016/j. flowmeasinst.2014.10.014

84. Liu, S., Chen, Q., Wang, H. G., Jiang, F., Ismail, I., Yang, W. Q. Electrical Capacitance Tomography for Gas-Solids Flow Measurement for Circulating Fluidized Beds. Flow Measurement and Instrumentation, 2005, 16, 135-144. https://doi.org/10.1016/j.flowmeasinst.2005.02.013

85. Liu, Y., Wang, L., Zhu, Z. Numerical Study on Flow Characteristics of Rotor Pumps Including Cavitation. Proceedings of the Institution of Mechanical Engineers, Part C: Journal of Mechanical Engineering Science, 2015, 229, 2626-2638. https://oi. org/10.1177/0954406214562634

86. Liu, Z., Babout, L., Banasiak, R., Sankowski, D. Effectiveness of Rotatable Sensor to Improve Image Accuracy of ECT System. Flow Measurement and Instrumentation, 2010, 21, 219-227. https://doi.org/10.1016/j.flowmeasinst.2010.03.005

87. Lucas, G. P., Cory, J., Waterfall, R. C., Loh, W. W., Dickin, F. J. Measurement of the Solids Volume Fraction and Velocity Distributions in Solids-Liquid Flows Using Dual-plane Electrical Resistance Tomography. Flow Measurement and Instrumentation, 1999, 10, 249-258. https://doi.org/10.1016/S0955-5986(99)00010-2

88. Lucas, G. P., Panagiotopoulos, N. Oil Volume Fraction and Velocity Profiles in Vertical, Bubbly Oil-in-Water Flows. Flow Measurement and Instrumentation, 2009, 20, 127-135. https://doi.org/10.1016/j.flowmeasinst.2009.02.005

89. Luggar, R. D., Key, M. J., Morton, E. J., Gilboy, W. B. Energy Dispersive X-ray Scatter for Measurement of Oil/Water Ratios. Nuclear Instruments and Methods in Physics Research Section A: Accelerators, Spectrometers, Detectors and Associated Equipment, 1999, 422, 938-941. https://doi.org/10.1016/S01689002(98)01050-X

90. Ma, L., Hunt, A., Soleimani, M. Experimental Evaluation of Conductive Flow Imaging Using Magnetic Induction Tomography. International Journal of Multiphase Flow, 2015, 72, 198-209. https://doi.org/10.1016/j. ijmultiphaseflow.2015.02.013
91. Mahvash, A., Ross, A. Two-phase Flow Pattern Identification Using Continuous Hidden Markov Model. International Journal of Multiphase Flow, Pergamon, 2008, 34, 303-311. https://doi.org/10.1016/j.ijmultiphaseflow.2007.08.006

92. Majchrowicz, M., Kapusta, P., Jackowska-Strumiłło, L., Sankowski, D. Acceleration of Image Reconstruction Process in the Electrical Capacitance Tomography 3D in Heterogeneous, Multi-GPU System. Informatics Control Measurement in Economy and Environment Protection, 2017, 7, 37-41. https://doi. org/10.5604/01.3001.0010.4579

93. Malijevsky, A., Archer, A.J. Sedimentation of a Two-dimensional Colloidal Mixture Exhibiting Liquid-Liquid and Gas-Liquid Phase Separation: A Dynamical Density Functional Theory Study. The Journal of Chemical Physics, American Institute of Physics, 2013, 139. https://doi.org/10.1063/1.4823768

94. Mandhane, J. M., Gregory, G. A., Aziz, K. A Flow Pattern Map for Gas-Liquid Flow in Horizontal Pipes. International Journal of Multiphase Flow, 1974, 1, 537-553. https://doi.org/10.1016/0301-9322(74)90006-8

95. Marashdeh, Q., Warsito, W., Fan, L.-S., Teixeira, F. Dual Imaging Modality of Granular Flow Based on ECT Sensors. Granular Matter, Springer-Verlag, 2008, 10, 7580. https://doi.org/10.1007/s10035-007-0070-2

96. Mazurkiewicz, L., Banasiak, R., Wajman, R., Dyakowski, T., Sankowski, D. Towards 3D Capacitance Tomography. 4th World Congress in Industrial Process Tomography, 2005.

97. Di Meglio, F., Kaasa, G.-O., Petit, N., Alstad, V. Model-based Control of Slugging Flow: An Experimental Case Study. Proceedings of the 2010 American Control Conference, IEEE, 2010, 2995-3002. https://doi. org/10.1109/ACC.2010.5531271

98. de Mesquita, C. H., Velo, A. F., Carvalho, D. V. S., Martins, J. F. T., Hamada, M. M. Industrial Tomography Using Three Different Gamma Ray. Flow Measurement and Instrumentation, 2016, 47, 1-9. https://doi. org/10.1016/j.flowmeasinst.2015.10.001

99. de Mesquita, R. N., Masotti, P. H. F., Penha, R. M. L., Andrade, D. A., Sabundjian, G., Torres, W. M., Macedo, L. A. Classification of Natural Circulation Two-phase Flow Patterns Using Fuzzy Inference on Image Analysis. Nuclear Engineering and Design, 2012, 250, 592-599. https://doi.org/10.1016/j.nucengdes.2012.06.014

100. Metherall, P., Barber, D. C., Smallwood, R. H., Brown, B. $\mathrm{H}$. Three-dimensional Electrical Impedance Tomogra- 
phy. Nature, Nature Publishing Group, 1996, 380, 509512. https://doi.org/10.1038/380509a0

101. Mewes, D., Wiemann, D. Two-phase Flow with Mass Transfer in Bubble Columns. Chemical Engineering \& Technology, WILEY-VCH Verlag, 2003, 26, 862-868. https://doi.org/10.1002/ceat.200300009

102. Mi, Y., Ishii, M., Tsoukalas, L. H. Flow Regime Identification Methodology with Neural Networks and Two-phase Flow Models. Nuclear Engineering and Design, North-Holland, 2001, 204, 87-100. https://doi. org/10.1016/S0029-5493(00)00325-3

103. Mosorov, V., Sankowski, D., Mazurkiewicz, Ł., Dyakowski, T. The „best-Correlated Pixels“ Method for Solid Mass Flow Measurements Using Electrical Capacitance Tomography. Measurement Science and Technology, IOP Publishing, 2002, 13, 1810-1814. https://doi. org/10.1088/0957-0233/13/12/302

104. Na, W., Jia, J., Yu, X., Faraj, Y., Wang, Q., Meng, Y., Wang, M., Sun. W. Imaging of Gas-Liquid Annular Flows for Underbalanced Drilling Using Electrical Resistance Tomography. Flow Measurement and Instrumentation, 2015, 46, 319-326. https://doi.org/10.1016/j.flowmeasinst.2015.07.003

105. Nguyen, T. T., Murakawa, H., Tsuzuki, N., Duong, H. N., Kikura, H. Ultrasonic Doppler Velocity Profile Measurement of Single- and Two-phase Flows Using Spike Excitation. Experimental Techniques, Wiley/Blackwell (10.1111). 2015, 40(4), 1235-1248. https://doi. org/10.1111/ext.12165

106. Nowakowski, J., Ostalczyk, P., Sankowski, D. Application of Fractional Calculus for Modelling of Two-phase Gas/Liquid Flow System. Informatics Control Measurement in Economy and Environment Protection, 2017, 7, 42-45. https://doi.org/10.5604/01.3001.0010.4580

107. Nygaard, G., Naevdal, G. Modelling Two-phase Flow for Control Design in Oil Well Drilling. Proceedings of 2005 IEEE Conference on Control Applications, 2005 CCA 2005, IEEE, 2005, 675-680. https://doi. org/10.1109/CCA.2005.1507205

108. Ogazi, A. I. Multiphase Severe Slug Flow Control [Internet]. Cranfield University, 2011.

109. Olesen, A. C., Romer, C., Kaer, S. K. A Numerical Study of the Gas-Liquid, Two-phase Flow Maldistribution in the Anode of a High Pressure PEM Water Electrolysis Cell. International Journal of Hydrogen Energy, 2016, 41, 5268. https://doi.org/10.1016/j.ijhydene.2015.09.140

110. Oshinowo, T., Charles, M. E. Vertical Two-phase Flow Part I. Flow Pattern Correlations. The Canadian Jour- nal of Chemical Engineering, 1974, 52, 25-35. https:// doi.org/10.1002/cjce.5450520105

111. Ozbayoglu, E. M., Ozbayoglu, M. A. Estimating Flow Patterns and Frictional Pressure Losses of Two-phase Fluids in Horizontal Wellbores Using Artificial Neural Networks. Petroleum Science and Technology, Taylor \& Francis Group, 2009, 27, 135-149. https://doi. org/10.1080/10916460701700203

112. Piotrowski, R., Błaszkiewicz, K., Duzinkiewicz, K. Analysis the Parameters of the Adaptive Controller for Quality Control of Dissolved Oxygen Concentration. Information Technology and Control, 2016, 45, 42-51. https://doi.org/10.5755/j01.itc.45.1.9246

113. Pląskowski A., Beck M. S., Thorn R., D. T. Imaging Industrial Flows - Applications of Electrical Process Tomography. IOP Publishing, Bristol. 1995.

114. Polydorides, N., Lionheart, W. R. B. A Matlab Toolkit for Three-dimensional Electrical Impedance Tomography: A Contribution to the Electrical Impedance and Diffuse Optical Reconstruction Software Project. Measurement Science and Technology, IOP Publishing, 2002, 13, 1871-1883. https://doi.org/10.1088/09570233/13/12/310

115. Poornapushpakala, S. Simulation of Neuro-Fuzzy Controller for a Flow Process Using MATLAB. 2015 International Conference on Circuits, Power and Computing Technologies [ICCPCT-2015], IEEE, 2015, 1-4. https://doi.org/10.1109/ICCPCT.2015.7159336

116. Pruna, E., Andaluz, V. H., Proano, L. E., Carvajal, C. P., Escobar, I., Pilatasig, M. Construction and Analysis of PID, Fuzzy and Predictive Controllers in Flow System. 2016 IEEE International Conference on Automatica (ICA-ACCA), IEEE, 2016, 1-7. https://doi.org/10.1109/ ICA-ACCA.2016.7778493

117. Qiao, J., Han, G., Han, H., Yang, C., Li, W. A Hybrid Intelligent Optimal Control System Design for Wastewater Treatment Process. Information Technology and Control, 2017, 46, 382-394. https://doi.org/10.5755/j01. itc.46.3.16061

118. Rabinovich, E., Kalman, H. Flow Regime Diagram for Vertical Pneumatic Conveying and Fluidized Bed Systems. Powder Technology, 2011, 207, 119-133. https:// doi.org/10.1016/j.powtec.2010.10.017

119. Ratajczak, M., Gundrum, T., Stefani, F., Wondrak, T. Contactless Inductive Flow Tomography: Brief History and Recent Developments in Its Application to Continuous Casting. Journal of Sensors, Hindawi, 2014, 1-9. https://doi.org/10.1155/2014/739161 
120. Reinecke, N., Mewes, D. Recent Developments and Industrial/Research Applications of Capacitance Tomography. Measurement Science and Technology, IOP Publishing. 1996, 7, 233-246. https://doi. org/10.1088/0957-0233/7/3/004

121. Ren, Z., Kowalski, A., Rodgers, T. L. Measuring Inline Velocity Profile of Shampoo by Electrical Resistance Tomography (ERT). Flow Measurement and Instrumentation, 2017, 58, 31-3\%. https://doi.org/10.1016/j. flowmeasinst.2017.09.013

122. Romanowski, A., Grudzien, K., Chaniecki, Z., Wozniak, P. Contextual Processing of ECT Measurement Information Towards Detection of Process Emergency States. 13th International Conference on Hybrid Intelligent Systems (HIS 2013), IEEE, 2013, 291-297. https:// doi.org/10.1109/HIS.2013.6920448

123. Romanowski, A., Grudzień, K., Garbaa, H., Jackowska-Strumiłło, L. Parametric Methods for ECT Inverse Problem Solution in Solid Flow Monitoring. Informatics Control Measurement in Economy and Environment Protection, 2017, 7, 50-54. https://doi. org/10.5604/01.3001.0010.4582

124. Romanowski, A., Grudzien, K., Williams, R. A. Analysis and Interpretation of Hopper Flow Behaviour Using Electrical Capacitance Tomography. Particle \& Particle Systems Characterization, WILEY-VCH Verlag, 2006, 23, 297-305. https://doi.org/10.1002/ppsc.200601060

125. Ruspini, L. C., Marcel, C. P., Clausse, A. Two-phase Flow Instabilities: A Review. International Journal of Heat and Mass Transfer, 2014, 71, 521-48. https://doi. org/10.1016/j.ijheatmasstransfer.2013.12.047

126. Rybak, G., Chaniecki, Z., Grudzień, K., Romanowski, A., Sankowski, D. Non-invasive Methods of Industrial Processes Control. Informatics Control Measurement in Economy and Environment Protection, 2014, 4, 4145. https://doi.org/10.5604/20830157.1121349

127. Rymarczyk, T. Topological Algorithms to Solve Inverse Problem in Electrical Tomography. Informatics Control Measurement in Economy and Environment Protection, 2017, 7, 55-58. https://doi. org/10.5604/01.3001.0010.4583

128. Rymarczyk, T., Tchorzewski, P., Adamkiewicz, P., Duda, K., Szumowski, J., Sikora, J. Practical Implementation of Electrical Tomography in a Distributed System to Examine the Condition of Objects. IEEE Sensors Journal, 2017, 17, 8166-8186. https://doi.org/10.1109/ JSEN.2017.2746748

129. Sætre, C., Tjugum, S.-A., Anton Johansen, G. Tomographic Segmentation in Multiphase Flow Measu- rement. Radiation Physics and Chemistry, Pergamon, 2014, 95, 420-423. https://doi.org/10.1016/j. radphyschem.2013.03.025

130. Sankowski, D., Nowakowski, J., Hammer, E., Babout, L., Banasiak, R., Chaniecki, Z, Grudzien, K., Janaszewski, M., Mosorow, W., Romanowski, A., Wajman, R. A Method and a Device for Measuring Component Fractions in a Multi-phase Flow [Internet]. Google Patents, Poland. EP 2416127 A1, 2012.

131. Santoro, R. J., Semerjian, H. G., Emmerman, P. J., Goulard, R. Optical Tomography for Flow Field Diagnostics. International Journal of Heat and Mass Transfer, Pergamon, 1981, 24, 1139-1150. https://doi. org/10.1016/0017-9310(81)90163-0

132. Shanthi, C., Pappa, N., Suganya, J. A. Digital Image Processing Based Flow Regime Identification of Gas/ Liquid Two-phase Flow. IFAC Proceedings Volumes, 2013, 46, 409-414. https://doi.org/10.3182/201312183-IN-2045.00170

133. Shi, Y. Y., Wang, M. Analytical Investigation of an Inductive Flow Sensor with Arc-shaped Electrodes for Water Velocity Measurement in Two-phase Flows. Flow Measurement and Instrumentation, 2015, 41, 9096. https://doi.org/10.1016/j.flowmeasinst.2014.10.019

134. Skogestad, S., Postlethwaite, I. Multivariable Feedback Control: Analysis and Design. John Wiley, 2005.

135. Smolik, W., Kryszyn, J., Olszewski, T., Szabatin, R. Methods of Small Capacitance Measurement in Electrical Capacitance Tomography. Informatics Control Measurement in Economy and Environment Protection, 2017, 7, 105-110. https://doi.org/10.5604/01.3001.0010.4596

136. Snyder, R., Hesselink, L. Measurement of Mixing Fluid Flows with Optical Tomography. Optics Letters, Optical Society of America, 1988, 13, 87-89. https://doi. org/10.1364/OL.13.000087

137. Soleimani, M., Wang, H., Li, Y. Y. W. A Comparative Study Of 3D Electrical Capacitance Tomography. International Journal For Information Systems Sciences, 2007, 3, 283-291.

138. Soleimani, M. Super-sensing Through Industrial Process Tomography. Philosophical Transactions Series A, Mathematical, Physical, and Engineering Sciences, The Royal Society, 2016, 374, 1-5. https://doi. org/10.1098/rsta.2015.0445

139. Solotych, V., Lee, D., Kim, J., Amalfi, R. L., Thome, J. R. Boiling Heat Transfer and Two-phase Pressure Drops within Compact Plate Heat Exchangers: Experiments and Flow Visualizations. International Journal of Heat 
and Mass Transfer, 2016, 94, 239-253. https://doi.org/10.1016/j.ijheatmasstransfer.2015.11.037

140. Storkaas, E., Skogestad, S. Controllability Analysis of Two-phase Pipeline-riser Systems at Riser Slugging Conditions. Control Engineering Practice, 2007, 15, 567-581. https://doi.org/10.1016/j.conengprac.2006.10.007

141. Tahir, A. M., Iqbal, J., Aized, T. Human Machine Interface: Robotizing the Instinctive Living. International Robotics \& Automation Journal, MedCrave Online, 2018, 4, 1-10. https://doi.org/10.15406/iratj.2018.04.00142

142. Taitel, Y. Stability of Severe Slugging. International Journal of Multiphase Flow, 1986, 12, 203-21\%. https:// doi.org/10.1016/0301-9322(86)90026-1

143. Takeda, Y. Velocity Profile Measurement by Ultrasonic Doppler Method. Experimental Thermal and Fluid Science, 1995, 10, 444-453. https://doi.org/10.1016/0894-177r7(94)00124-Q

144. Teng, P., Yang, J., Pfister, M. Studies of Two-phase Flow at a Chute Aerator with Experiments and CFD Modelling. Modelling and Simulation in Engineering, Hindawi Publishing Corporation, 2016, 2016, 1-11. https:// doi.org/10.1155/2016/4729128

145. Thorn, R., Johansen, G. A., Hjertaker, B. T. Three-phase Flow Measurement in the Petroleum Industry. Measurement Science and Technology, IOP Publishing, 2013, 24, 012003. https://doi.org/10.1088/09570233/24/1/012003

146. Ulbrich, R., Krótkiewicz, M., Szmolke, N., Anweiler, S., Masiukiewicz, M., Zajac, D. Recognition of Two-phase Flow Patterns with the Use of Dynamic Image Analysis. Proceedings of the Institution of Mechanical Engineers, Part E: Journal of Process Mechanical Engineering, SAGE PublicationsSage UK: London, England, 2002, 216, 227-233. https://doi. org/10.1243/095440802321194503

147. Vadlakonda, B., Mangadoddy, N. Hydrodynamic Study of Two Phase Flow of Column Flotation Using Electrical Resistance Tomography and Pressure Probe Techniques. Separation and Purification Technology, 2017, 184, 168-187. https://doi.org/10.1016/j.seppur.2017.04.029

148. Venkata, S. K., Roy, B. K. An Intelligent Flow Measurement Scheme Using Ultrasonic Flow Meter. International Journal of Control and Automation, 2012, 5(4), 185-195.https://doi.org/10.2316/P.2012.769-033

149. Wajman, R., Banasiak, R. Tunnel-based Method of Sensitivity Matrix Calculation for 3D-ECT Imaging. Sen- sor Review, 2014, 34, 273-83. https://doi.org/10.1108/ SR-06-2013-692

150. Wajman, R., Banasiak, R., Mazurkiewicz, L., Dyakowski, T., Sankowski, D. Spatial Imaging with 3D Capacitance Measurements. Measurement Science and Technology, 2006, 18, 3671-3671. https://doi.org/10.1088/09570233/18/11/C01

151. Wajman, R., Fiderek, P., Fidos, H., Jaworski, T., Nowakowski, J., Sankowski, D, Banasiak, R. Metrological Evaluation of a 3D Electrical Capacitance Tomography Measurement System for Two-phase Flow Fraction Determination. Measurement Science and Technology, 2013, 24, 065302. https://doi.org/10.1088/09570233/24/6/065302

152. Waleska, B., Sikora, J. Boundary Element Method and Set Level Method in Electrical Diffuse Tomography. Informatics Control Measurement in Economy and Environment Protection, 2012, 2, 3-6.

153. Wang, B., Gui, Z., Tan, W., Huang, Z., Ji, H., Li, H. A New Dual-modality ECT/ERT Technique Based on C4Dprinciple. 2015 IEEE International Instrumentation and Measurement Technology Conference (I2MTC) Proceedings, IEEE, 2015, 2061-2065. https://doi. org/10.1109/I2MTC.2015.7151600

154. Wang, H., Liu, S., Fan, J., Yang, W. 3D Presentation of Images with Capacitance Tomography. 3rd World Congress on Industrial Process Tomography, Banff, Canada. 2003, 331-336.

155. Wang, N., Tan, C., Dong, F. Water Holdup Measurement of Oil-Water Two-phase Flow Based on KPLS Regression. 2015 Chinese Automation Congress (CAC), IEEE, 2015, 1896-900. https://doi.org/10.1109/ CAC.2015.7382813

156. Warsito, W., Fan, L.-S. Dynamics of Spiral Bubble Plume Motion in the Entrance Region of Bubble Columns and Three-phase Fluidized Beds Using 3D ECT. Chemical Engineering Science, 2005, 60, 6073-6084. https://doi.org/10.1016/j.ces.2005.01.033

157. Wu, H., Tan, C., Dong, X., Dong, F. Design of a Conductance and Capacitance Combination Sensor for Water Holdup Measurement in Oil-Water Two-phase Flow. Flow Measurement and Instrumentation, 2015, 46, 218-29. https://doi.org/10.1016/j.flowmeasinst.2015.06.026

158. Xie, C. G., Huang, S. M., Beck, M. S., Hoyle, B. S., Thorn, R., Lenn, C. , Snowden, D. Electrical Capacitance Tomography for Flow Imaging: System Model for Development of Image Reconstruction Algorithms and De- 
sign of Primary Sensors. IEE Proceedings G Circuits, Devices and Systems, 1992, 139, 89-98. hhttps://doi. org/10.1049/ip-g-2.1992.0015

159. Xie, D., Huang, Z., Ji, H., Li, H. An Online Flow Pattern Identification System for Gas-Oil Two-phase Flow Using Electrical Capacitance Tomography. IEEE Transactions on Instrumentation and Measurement, 2006, 55, 1833-1838. https://doi.org/10.1109/ TIM.2006.881558

160. Xie, T., Ghiaasiaan, S. M., Karrila, S. Artificial Neural Network Approach for Flow Regime Classification in Gas-Liquid-Fiber Flows Based on Frequency Domain Analysis of Pressure Signals. Chemical Engineering Science, 2004, 59, 2241-2251. https://doi.org/10.1016/j. ces.2004.02.017

161. Xu, L., Han, Y., Xu, L.-A., Yang, J. Application of Ultrasonic Tomography to Monitoring Gas/Liquid Flow. Chemical Engineering Science, Pergamon, 1997, 52, 217183. https://doi.org/10.1016/S0009-2509(9r)00043-2

162. Yan, C., Liao, Y. Design of a New Optical Fiber Process Tomography Configuration with High Image Reconstruction Resolution. Sensors and Actuators B: Chemical, 2013, 186,186-192. https://doi.org/10.1016/j.snb.2013.06.001

163. Yang, W. Q., Peng, L. Image Reconstruction Algorithms for Electrical Capacitance Tomography. Measurement Science and Technology, IOP Publishing, 2003, 14, R113. https://doi.org/10.1088/0957-0233/14/1/201

164. York, T., Mazurkiewicz, L., Polydorides, N., Mann, R., Grieve, B. Image Reconstruction for Pressure Filtrati- on Using EIDORS 3D. 3rd World Congress on Industrial Process Tomography, 2003, 559.

165. Yunus, F. R. M., Rahim, R. A., Aw, S. R., Ayob, N. M. N., Goh, C. L., Pusppanathan, M. J. Simulation Study of Electrode Size in Air-Bubble Detection for Dual-mode Integrated Electrical Resistance and Ultrasonic Transmission Tomography. Powder Technology, 2014, 256, 224-232. https://doi.org/10.1016/j.powtec.2014.02.001

166. Zargaran, A., Mozaffari, E., Giddings, D. Gas-Liquid Slip Velocity Determination in Co-current Column Flotation. Separation and Purification Technology, 2016, 169, 179-186. https://doi.org/10.1016/j.seppur.2016.05.018

167. Zhai, L., Jin, N., Gao, Z., Wang, Z. Liquid Holdup Measurement with Double Helix Capacitance Sensor in Horizontal Oil-Water Two-phase Flow Pipes. Chinese Journal of Chemical Engineering, 2015, 23, 268-275. https://doi.org/10.1016/j.cjche.2014.10.010

168. Zhai, L. S., Jin, N. D., Gao, Z. K., Zhao, A., Zhu, L. Cross-correlation Velocity Measurement of Horizontal Oil-Water Two-phase Flow by Using Parallel-Wire Capacitance Probe. Experimental Thermal and Fluid Science, 2014, 53, 277-289. https://doi.org/10.1016/j. expthermflusci.2013.12.021

169. Zhu, Z. T., Wang, Y., Zhao, L. F., Ning, C., Xie, S. F., Liu, Z. C. The Effect of Gas Fraction on Centrifugal Pump. IOP Conference Series: Materials Science and Engineering, IOP Publishing, 2015, 72, 032022. https://doi. org/10.1088/1757-899X/72/3/032022 